\title{
DINAMIKA POPULASI LAMUN Thalassia hemprichii PADA PERAIRAN PANTAI LATERI, TELUK AMBON DALAM
}

\author{
Charlotha I. Tupan ${ }^{1, *}$ \\ ${ }^{1}$ Fakultas Perikanan dan Ilmu Kelautan, Universitas Pattimura, Ambon \\ J1 Mr. Chr. Soplanit, Poka, Ambon, Indonesia \\ *Koresponden penulis : lotjetupan@yahoo.com
}

\begin{abstract}
Abstrak
Penelitian dinamika populasi telah banyak dilakukan terhadap hewan, namun pada tumbuhan masih jarang. Selama ini penelitian pertumbuhan lamun lebih banyak dilakukan dengan cara pengukuran panjang daun. Namun demikian pertumbuhan lamun dapat diketahui selain melalui panjang daun juga melalui panjang rhizoma. Dengan rhizoma dapat diketahui umur, sekaligus dapat diestimasi laju rekruitmen dan laju mortalitas. Penelitian ini bertujuan untuk mengetahui pertumbuhan rhizoma horizontal dan vertikal, estimasi struktur umur, laju rekruitmen dan laju mortalitas serta menentukan status populasi dari lamun Thalassia hemprichii dengan menggunakan teknik rekonstruksi. Penentuan umur lamun berdasarkan interval plastochrone. Laju rekruitmen diestimasi dari struktur umur tegakkan hidup, sedangkan laju mortalitas diestimasi dari struktur umur tegakkan mati. Penelitian ini dilakukan pada bulan April 2017. Laju pertumbuhan rhizoma horizontal diperoleh sebesar $9.41 \mathrm{~cm} . \mathrm{thn}^{-1}$, dan laju pertumbuhan rhizoma vertikal sebesar $1.30 \mathrm{~cm} \cdot \mathrm{chn}^{-1}$. Tegakan lamun . hemprichii paling muda ditemukan berumur 0.08 tahun dan paling tua berumur 7.44 tahun. Distribusi umur memperlihatkan beberapa model, yang mencerminkan adanya kohort. Laju rekruitmen diperoleh sebesar $0.98 \mathrm{thn}^{-1}$, dan laju mortalitas sebesar $1.12 \mathrm{thn}^{-1}$. Populasi lamun T. hemprichii Perairan Pantai Lateri, Teluk Ambon Dalam, berada pada kondisi penurunan yang ditunjukkan dengan nilai rekruitmen yang lebih kecil dari pada nilai mortalitas.
\end{abstract}

Kata Kunci: mortalitas, rekruitmen, rhizoma, T. hemprichii, umur

\begin{abstract}
Population dynamics research has been carried out on animals, but still rare in plants. So far, researches on seagrass growth mostly have been done by measuring the length of leaves. However, seagrass growth can be known not only through the length of leaves but also through the length of rhizomes. From rhizomes, the age of seagrass, the recruitment rate and mortality rate can be estimated. This study was to determine the growth of horizontal and vertical rhizomes, the estimation of age structure, the rate of recruitment and mortality also to determine the population status of Thalassia hemprichii using reconstruction techniques. The age determination was based on the plastochrone interval. The recruitment rate was estimated from the age structure of the living shoot, while the mortality rate was estimated from the age structure of a dead shoot. This research was conducted in April 2017. Horizontal rhizome growth rate was obtained at 9.41 cm.year ${ }^{-1}$, and vertical rhizoma growth rate was at $1.30 \mathrm{~cm}$.year ${ }^{-1}$. The youngest $T$. hemprichii shoot was 0.08 years old and the oldest was 7.44 years old. Age distribution shows several models, which reflect a cohort. The recruitment rate was $0.98 \mathrm{yr}^{-1}$, and the mortality rate was $1.12 \mathrm{yr}^{-1}$. T. hemprichii population at Lateri Coastal Waters, Inner Ambon Bay, was decreasing indicated by smaller recruitment value than mortality value.
\end{abstract}

Keywords: age, mortality, recruitment, rhizome, T. hemprichii

\section{PENDAHULUAN}

Lamun merupakan salah satu ekosistem pesisir yang tumbuh dengan subur pada daerah pasang surut, perairan pantai atau laguna dimana dasar perairannya berupa lumpur, pasir, kerikil dan patahan karang mati dengan kedalaman sampai 4 meter [1]. Pada perairan yang jernih, lamun dapat ditemukan tumbuh mencapai kedalaman 8-15 meter bahkan sampai 40 meter [2]. Ekosistem ini dapat dijumpai di Teluk Ambon Dalam, khususnya pada Perairan Pantai Lateri. Salah satu spesies lamun yang ditemukan melimpah 
pada perairan ini adalah Thalassia hemprichii $[3,4]$.

Lamun memiliki fungsi fisik seperti perangkap sedimen, menstabilkan sedimen dasar, meredam gelombang dan energi arus, selain itu juga memiliki fungsi ekologi seperti menyediakan habitat penting dan tempat berlindung untuk sejumlah spesies hewan, dan habitat yang kaya dengan zat-zat hara bagi keragaman flora dan fauna [5,6]. Dengan demikian lamun dapat dimanfaatkan sebagai tempat pemancingan, wisata bahari, bahan baku pakan untuk ikan dan hewan ternak serta areal budidaya. Pemanfaatan potensi padang lamun tersebut dapat meningkatkan kesejahteraan masyarakat, namun demikian jika pemanaatan yang dilakukan tanpa memperhatikan pengelolaan yang berkelanjutan maka akan mengurangi fungsi dari ekosistem tersebut.

Aktivitas masyarakat pesisir dalam memanfaatkan sumberdaya padang lamun, seringkali menimbulkan dampak negatif terhadap kelestariannya. Aktivitas manusia yang sering mengancam padang lamun diantaranya dampak aktivitas penangkapan ikan, buangan limbah dan sampah, pencemaran, aktivitas rekreasi, aktivitas pelayaran dan tempat berlabuh serta buangan limbah industri pabrik. Hal ini dapat terjadi salah satunya karena kurangnya informasi tentang lamun.

Informasi biologis dari ekosistem lamun masih dirasakan kurang terutama dinamika populasinya. Oleh sebab itu diperlukan suatu penelitian tentang aspek biologis dari ekosistem tersebut. Pertumbuhan lamun dapat diukur dari pertambahan panjang bagianbagian lamun seperti daun dan rhizoma dalam kurun waktu tertentu. Selama ini penelitian pertumbuhan lamun sebagian besar dilakukan dengan cara pengukuran panjang daun. Dibandingkan pertumbuhan daun, pertumbuhan rhizoma lebih sulit diukur khususnya untuk jenis-jenis tertentu yang rhizoma masuk jauh ke dalam substrat [7]. Pengukuran pertumbuhan pada penelitian ini difokuskan pada pertambahan panjang rhizoma vertikal dan horizontal. Dengan rhizoma dapat diketahui pertumbuhan, sekaligus dapat diketahui umur, laju rekruitmen dan laju mortalitas [8].

Tujuan dari penelitian ini adalah mengetahui dinamika populasi dari jenis lamun $T$. hemprichii yang meliputi pertumbuhan rhizoma, struktur umur, laju rekruitmen dan laju mortalitas, serta menentukan status populasi lamun $T$. hemprichii pada perairan Pantai Lateri, Teluk Ambon Dalam.

\section{METODE PENELITIAN}

Penelitian ini dilakukan pada perairan Pantai Lateri Teluk Ambon Dalam, pada Bulan April 2017 (Gambar 1).

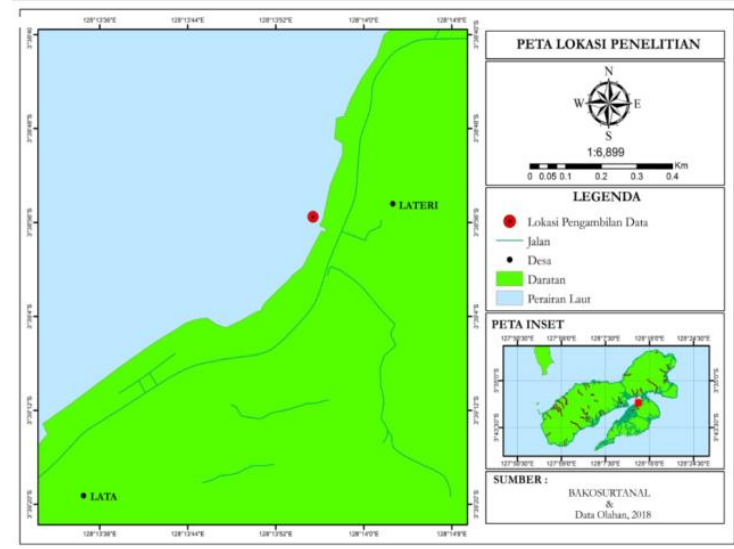

Gambar 1. Peta Lokasi Penelitian

Pengumpulan sampel lamun dilakukan dalam kuadrat ukuran 1 x $1 \mathrm{~m}$, yang diletakan secara acak pada padang lamun monospesifik $T$ hemprichii, yang meliputi minimal 200 tegakan [9]. Lamun dipisahkan dari sedimen secara hati-hati untuk mencegah terputusnya akar dan rhizoma horizontal antar tegakan satu dengan lainnya. Sampel lamun kemudian dihitung jumlah tegakan hidup dan tegakan mati, jumlah noda dan internoda vertikal dan jumlah noda dan internoda horizontal, jumlah daun, jumlah akar hidup dan akar mati serta mengukur panjang dan lebar daun, panjang rhizoma horizontal antar tegakan dan panjang rhizoma vertikal (Gambar 2). 


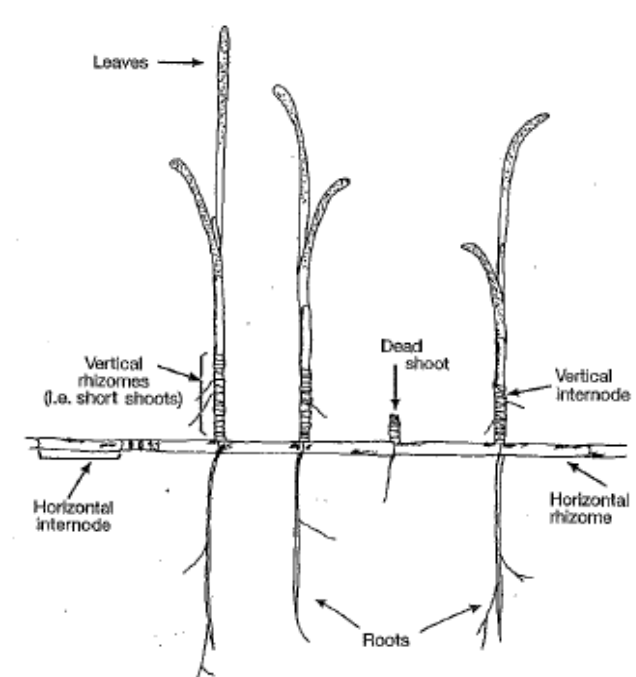

Gambar 2. Morfologi lamun [8].

\section{Metode Analisis Data}

Penggunaan unit umur lamun berkaitan dengan rata-rata interval waktu antara pertumbuhan dua daun secara berurutan pada tegakan dan disebut dengan interval plastochrone [10, 9, 11]. Estimasi umur yang dihasilkan dalam unit interval plastochrone kemudian dikonversi ke dalam unit waktu absolut.

Laju pertumbuhan rhizoma horizontal diestimasi sebagai kemiringan persamaan regresi linier antara panjang rhizoma diantara tegakan yang tersambung di sepanjang potongan rhizoma (y) dan perbedaan umur tegakan. Demikian pula, laju pertumbuhan rhizoma vertikal diestimasi sebagai kemiringan regresi linier antara panjang rhizoma vertikal (y) dan umur tegakan.

Laju rekruitmen (dalam unit per tahun) diestimasi dari total jumlah tegakan $\left(\sum_{t=0}^{\infty} N_{t}\right)$ dan jumlah tegakan lebih dari satu tahun $\left(\sum_{t=1}^{\infty} N_{t}\right)$ yang terdapat dalam populasi tersebut $[8,9,11]$, sebagai berikut:

$$
R_{\text {gross }}=\ln \sum_{t=0}^{\infty} N_{t}-\ln \sum_{t=1}^{\infty} N_{t}
$$

Laju mortalitas dihitung berdasarkan penurunan eksponensial dari jumlah tegakan yang mati dengan umur, dan memungkinkan estimasi laju mortalitas tegakan eksponensial (M, dalam unit per waktu)

$$
N_{t}=N_{0} e^{-M t}
$$

$\mathrm{N}_{0}$ adalah jumlah tegakan mati dengan umur yang sama dengan model, dan $\mathrm{N}_{\mathrm{t}}$ adalah jumlah tegakan yang mati pada suatu interval umur pada waktu $t$ [8]. Laju pertumbuhan populasi bersih dihitung sebagai perbedaan diantara rekruitmen tahunan dan mortalitas.

Mortalitas dan rekruitmen digunakan untuk mengevaluasi status padang lamun dan untuk memprediksi pertumbuhannya [8].

Jika

$$
\begin{aligned}
& \mathrm{R}>\mathrm{M}=\text { Populasi meningkat } \\
& \mathrm{R}=\mathrm{M}=\text { Popuasi seimbang } \\
& \mathrm{R}<\mathrm{M}=\text { Populasi menurun }
\end{aligned}
$$

\section{HASIL DAN PEMBAHASAN}

\section{Pertumbuhan Rhizoma}

Lamun memiliki rhizoma yang terdiri dari internoda atau ruas dan noda tempat tumbuhnya daun diantara ruas. Beberapa jenis lamun memiliki dua jenis rhizoma, yaitu rhizoma vertikal (stem) yang ukuran internodanya lebih pendek dan rhizoma horizontal yang ukuran internodanya lebih panjang [12]. Rata-rata panjang rhizoma horizontal T. hemprichii diantara dua tegakkan adalah $5.51 \pm 2.50 \mathrm{~cm}$. Ukuran rhizoma paling pendek adalah $0.20 \mathrm{~cm}$ dan paling panjang adalah $13.00 \mathrm{~cm}$. Laju pertumbuhan rhizoma horizontal diperoleh sebesar $9.41 \mathrm{~cm} \cdot \mathrm{thn}^{-1}$ dan rhizoma vertikal sebesar $1.30 \mathrm{~cm}^{-\mathrm{thn}^{-1}}$. Rata-rata panjang rhizoma vertikal adalah $1.36 \pm 1.27 \mathrm{~cm}$, dimana ukuran terpanjang adalah $9.7 \mathrm{~cm}$ dan terpendek adalah $0.1 \mathrm{~cm}$.

Nilai pertumbuhan rhizoma horizontal maupun vertikal pada penelitian ini lebih kecil dibandingkan dengan nilai pertumbuhan rhizoma untuk jenis yang sama ( $T$. hemprichii) yang ditemukan di daerah Philippina [13], (Tabel 1). Vermat et al., (1995) [13] menemukan pertumbuhan rhizoma horizontal T. hemprichii sebesar 20.6 $\mathrm{cm} \cdot \mathrm{thn}^{-1}$ dan rhizoma vertikal sebesar 3.0 $\mathrm{cm} \cdot \mathrm{thn}^{-1}$. Nilai-nilai ini didukung oleh ukuran panjang rhizoma horizontal sebesar $6.9 \mathrm{~cm}$ dan rhizoma vertikal sebesar $6.24 \mathrm{~cm}$. Pertumbuhan rhizoma ini dipengaruhi oleh 
panjang rhizoma dan umur [8]. Secara morfologi ukuran panjang rhizoma yang ditemukan di Philippina lebih panjang dibandingkan dengan penelitian ini. Menurut Marba et al., (1994) [14] dan Duarte et al., (1997) [15] bahwa peningkatan jarak internode pada rhizoma vertikal yang dihasilkan dari pertumbuhan vertikal merupakan indikasi penguburan rhizoma oleh sedimen. Selain rhizoma, karakteristik morfometrik lain seperti daun juga lebih baik dibandingkan penelitian ini (Tabel 1).

Pertumbuhan rhizoma T. hemprichii pada Perairan Lateri ini tidak jauh berbeda dengan pertumbuhan rhizoma pada perairan lain di Pulau Ambon, seperti pada Perairan Tanjung Tiram Poka $\left(10.67 \mathrm{~cm} . \mathrm{thn}^{-1} / \mathrm{rhizoma}\right.$ horizontal; $1.09 \mathrm{~cm} \cdot \mathrm{thn}^{-1} /$ rhizoma vertikal) [16] dan Perairan Suli $\left(8.68 \mathrm{~cm} \cdot \mathrm{thn}^{-1} /\right.$ rhizoma horizontal; $1.11 \mathrm{~cm} \cdot \mathrm{thn}^{-1} /$ rhizoma vertikal) [17]. Pertumbuhan rhizoma mempengaruhi pertumbuhan lamun secara ekstensif, baik horizontal mapun vertikal, untuk membentuk padang lamun. Rhizoma horizontal merupakan penentu pertumbuhan lamun secara horizontal. Rhizoma vertikal dapat memproduksi rhizoma horizontal bila jaringan meristem apikal asli dari rhizoma horizontal telah mati (dari cabang rhizoma vertikal), sehingga rhizoma horizontal yang baru memiliki kapasitas untuk melanjutkan pertumbuhan lamun secara horizontal [12].

Tabel 1. Pertumbuhan rhizoma dan karakteristik morfometrik daun T. hemprichii

\begin{tabular}{|c|c|c|}
\hline $\begin{array}{l}\text { Pertumbuhan rhizoma dan } \\
\text { karakteristik morfometrik } \\
\text { daun }\end{array}$ & $\begin{array}{c}\text { Penelitian } \\
\text { ini }\end{array}$ & $\begin{array}{l}\text { Vermat et } \\
\text { al., (1995) }\end{array}$ \\
\hline $\begin{array}{l}\text { Rata-rata panjang rhizoma } \\
\text { horizontal antar tegakkan } \\
(\mathrm{cm})\end{array}$ & $5.51 \pm 2.50$ & 6.9 \\
\hline $\begin{array}{l}\text { Laju pertumbuhan rhizoma } \\
\text { horizontal }\left(\mathrm{cm} \cdot \mathrm{th}^{-1}\right)\end{array}$ & 9.41 & 20.6 \\
\hline $\begin{array}{l}\text { Rata-rata panjang rhizoma } \\
\text { vertikal }(\mathrm{cm})\end{array}$ & $1.36 \pm 1.27$ & $6.24 \pm 0.45$ \\
\hline $\begin{array}{l}\text { Laju pertumbuhan rhizoma } \\
\text { vertikal }\left(\mathrm{cm} \cdot \mathrm{thn}^{-1}\right)\end{array}$ & 1.30 & 3.0 \\
\hline $\begin{array}{l}\text { Rata-rata produksi daun } \\
\left(\text { daun.thn }{ }^{-1}\right)\end{array}$ & 12.71 & 34.8 \\
\hline Rata-rata panjang daun $(\mathrm{cm})$ & $5.01 \pm 2.05$ & $8.68 \pm 0.53$ \\
\hline Rata-rata lebar daun $(\mathrm{cm})$ & $0.67 \pm 0.16$ & $0.80 \pm 0.04$ \\
\hline Rata-rata jumlah daun $\left(\right.$ teg $\left.^{-1}\right)$ & $2.75 \pm 0.74$ & $3.29 \pm 0.03$ \\
\hline
\end{tabular}

\section{Struktur Umur}

Umur lamun diestimasi berdasarkan rata-rata interval waktu antara perkembangan dua daun yang berurutan pada satu tegakkan dan disebut sebagai interval plastochrone [10]. Interval plastochrone merepresentasikan estimasi waktu secara tidak langsung dan memberikan estimasi yang akurat pada skala waktu antar tahunan $[10,8]$. Umur lamun $T$. hemprichii dapat dilihat pada Tabel 2. Pada Tabel tersebut terlihat bahwa sebagian besar tegakkan lamun $T$. hemprichii yang ada pada Perairan Pantai Lateri didominasi oleh lamun berumur muda $(<2$ tahun), dimana $32 \%$ adalah lamun berumur $<0.5$ tahun, $27 \%$ adalah lamun berumur $0.50-0.99$ tahun, 18 $\%$ adalah lamun berumur $1.00-1.49$ tahun dan $11 \%$ adalah lamun berumur $1.50-1.99$ tahun.

Lamun muda ini dicirikan oleh ukuran rhizoma vertikal yang pendek, jumlah internoda dan noda vertikal yang sedikit serta jumlah daun yang sedikit. Dalam satu populasi, tegakkan lamun baru atau yang berumur muda juga memiliki jarak rhizoma horizontal antar tegakan lebih pendek. Lamun T. hemprichii paling muda diperoleh berumur 0.08 tahun dan paling tua berumur 7.44 tahun (Tabel 4). Tupan et al., (2016) [16] dan Tupan and Uneputty (2017) [17] menemukan lamun T. hemprichi pada Perairan Tanjung Tiram, Poka dan Perairan Suli berumur paling muda adalah 0.38 tahun dan paling tua berumur 7.36 dan 7.82 tahun. Kisaran umur tersebut tidak jauh berbeda dengan penelitian ini. Lamun berumur tua dicirikan oleh ukuran rhizoma vertikal yang panjang, jumlah internoda dan noda rhizoma vertikal lebih banyak, jumlah daun lebih banyak serta ukuran rhizoma horizontal antar tegakan lebih panjang. 
Tabel 2. Umur Lamun T. hemprichii yang hidup

\begin{tabular}{cr}
$\begin{array}{c}\text { Kisaran } \\
\text { umur (thn) }\end{array}$ & $\begin{array}{c}\text { Prosentase } \\
(\boldsymbol{\%})\end{array}$ \\
\hline $0.00-0.49$ & 32.80 \\
$0.50-0.99$ & 27.56 \\
$1.00-1.49$ & 18.00 \\
$1.50-1.99$ & 11.16 \\
$2.00-2.49$ & 3.87 \\
$2.50-2.99$ & 2.05 \\
$3.00-3.49$ & 0.91 \\
$3.50-3.99$ & 0.91 \\
$4.00-4.49$ & 0.46 \\
$4.50-4.99$ & 0.46 \\
$5.00-5.49$ & 0.68 \\
$5.50-5.99$ & 0.46 \\
$6.00-6.49$ & 0.00 \\
$6.50-6.99$ & 0.46 \\
$7.00-7.49$ & 0.23 \\
\hline & 100.00 \\
\hline
\end{tabular}

Struktur umur tegakkan mati dapat dilihat pada Tabel 3. Lamun T. hemprichii yang mati pada perairan ini berkisar pada umur $0-2.99$ tahun, dimana sebagian besar pada umur $0.50-0.99$ tahun $(31.78 \%)$ kemudian pada umur $0-0.49$ tahun (28.97 $\%)$. Data ini memperlihatkan bahwa sebagian besar lamun yang mati juga berada pada umur muda. Hal ini mengindikasikan bahwa populasi lamun $T$. hemprichii yang hidup pada perairan ini tidak dapat mempertahankan kelangsungan hidupnya sampai berumur tua, terindikasi dari persentase jumlah tegakkan hidup yang berumur $>3$ tahun hanya sebesar $<1 \%$.

Tabel 3. Umur Lamun T. hemprichii yang mati

\begin{tabular}{cr}
$\begin{array}{c}\text { Kisaran } \\
\text { umur (Thn) }\end{array}$ & $\begin{array}{c}\text { Prosentase } \\
(\boldsymbol{\%})\end{array}$ \\
\hline $0.00-0.49$ & 28.97 \\
$0.50-0.99$ & 31.78 \\
$1.00-1.49$ & 19.63 \\
$1.50-1.99$ & 12.15 \\
$2.00-2.49$ & 6.54 \\
$2.50-2.99$ & 0.93 \\
\hline & 100.00 \\
\hline
\end{tabular}

Tabel 4. Dinamika Populasi T hemprichii

\begin{tabular}{lrr}
\hline & $\begin{array}{c}\text { Penelitian } \\
\text { ini }\end{array}$ & $\begin{array}{c}\text { Vermat } \\
\text { et al., } \\
(\mathbf{1 9 9 5})\end{array}$ \\
\hline Umur rata-rata & $1.04 \pm 0.97$ & $1.83 \pm 0.07$ \\
Umur paling muda (thn) & 0.08 & - \\
Umur paling tua (thn) & 7.44 & - \\
Laju rekruitmen $\left(\mathrm{thn}^{-1}\right)$ & 0.98 & 0.77 \\
Laju mortalitas $\left(\mathrm{thn}^{-1}\right)$ & 1.12 & 0.48 \\
$\begin{array}{l}\text { Laju pertumbuhan } \\
\text { populasi bersih }\left(\mathrm{thn}^{-1}\right)\end{array}$ & -0.13 & 0.29 \\
\hline
\end{tabular}

\section{Mortalitas dan Rekruitmen}

Data umur pada Tabel 2 dan 3, kemudian dibuat distribusi umur dalam bentuk grafik (Gambar 3 dan 4). Gambar 3 memperlihatkan distribusi umur yang membentuk beberapa model yang mencerminkan adanya kohort atau kelompokkelompok umur. Menurut Duarte and SandJensen, (1990b) [18]; Duarte et al., (1994) [8] bahwa distribusi umur akan membentuk beberapa model, dengan model yang berbeda beda mewakili kohort tegakkan tahunan.

Jumlah tegakkan lamun $T$. hemprichii dalam populasi tersebut semakin menurun dengan bertambahnya umur dan memperlihatkan bentuk yang sangat miring mengindikasikan laju mortalitas yang tinggi. Laju mortalitas diperoleh sebesar $1.12 \mathrm{thn}^{-1}$ dan laju rekruitmen sebesar $0.98 \mathrm{thn}^{-1}$. Nilai motalitas ini lebih tinggi dibandingkan nilai mortalitas T. hemprichii pada perairan Poka dan Suli [16 , 17]. Supriadi (2006) [19] melaporkan bahwa pertumbuhan dan kelangsungan hidup lamun dipengaruhi oleh faktor-faktor internal seperti fisiologi dan metabolisme serta faktor eksternal seperti zatzat hara, tingkat kesuburan substrat dan faktor lingkungan lainnya. Hasil penelitian Cunha and Duarte (2005) [9] menunjukkan bahwa efek peningkatan eutrofikasi mengurangi rekruitmen dan kelangsungan hidup tegakkantegakkan lamun Cymodocea nodosa di Ria Formosa dan menunjukkan mortalitas yang tinggi. 


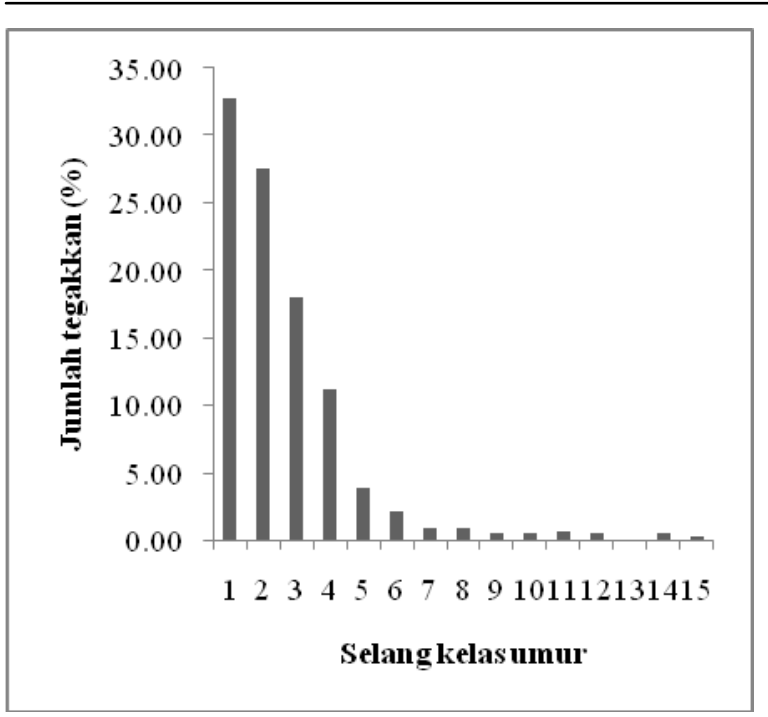

Gambar 3. Grafik distribusi umur T.hemprichii yang hidup

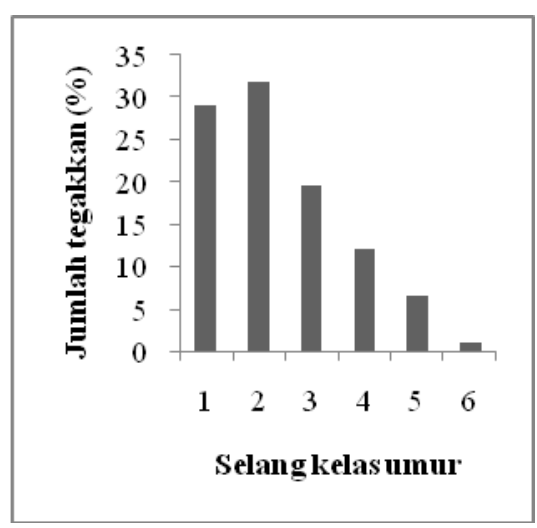

Gambar 4. Grafik distribusi umur T.hemprichii yang mati

Aktivitas pemanfaatan pada perairan pantai Lateri belakangan ini cukup tinggi, seperti adanya sedimentasi, aktivitas restoran apung dan jalur kapal yang masuk dan keluar Teluk Ambon memungkinkan menurunnya kualitas perairan. Penelitian Tupan (2014) [20] memperoleh kadar logam berat $\mathrm{Pb}$ pada Perairan Lateri sebesar $0.05-0.14 \mathrm{ppm}$. Kondisi ini diduga turut mempengaruhi pertumbuhan lamun. Menurut Ambo Rappe (2011) [21] pencemaran logam berat $\mathrm{Pb}$ dan $\mathrm{Cu}$ dapat mempengaruhi struktur mofologi dari lamun seperti memperpendek rhizoma dan mengurangi jumlah noda serta merubah struktur ukuran daun lamun Halophila ovalis. Selain itu kandungan logam $\mathrm{Pb}$ juga dapat menghambat pertumbuhan lamun $T$. hemprichii dengan mengurangi total kandungan klorofil pada daun [22].

Nilai mortalitas dan rekruitmen digunakan untuk menganalisis status populasi lamun dan mendapatkan bahwa status populasi lamun $T$. hemprichii pada Perairan Pantai Lateri sedang mengalami penurunan. Hal yang sama juga terjadi pada populasi lamun T. hemprichii Perairan Tanjung Tiram Poka [16]. Penurunan populasi lamun ini tercermin dari laju pertumbuhan populasi bersih yang rendah $\left(-0.13\right.$ thn $\left.^{-1}\right)$ seiring dengan pertumbuhan rhizoma yang terbatas yang mengurangi tekruitmen dari tegakkantegakkan lamun tersebut.

\section{KESIMPULAN}

Populasi lamun T. hemprichii Perairan Pantai Lateri memiliki pertumbuhan rhizoma yang terbatas, struktur umur yang cukup bervariasi, dan memiliki mortalitas yang tinggi serta laju rekruitmen yang rendah. Kondisi ini mengakibatkan populasi lamun ini berada pada kondisi penurunan.

\section{UCAPAN TERIMA KASIH}

Terima kasih kepada Alberth Pical, (mahasiswa S2 Ilmu Kelautan UNPATTI) dan Nita Luduwara, Dhelma Parmino serta Ratih Tianotak (Mahasiswa S1 Fakultas Perikanan dan Ilmu Kelautan UNPATTI) atas bantuan dalam pengambilan data di lapangan.

\section{DAFTAR PUSTAKA}

[1] R. Dahuri, "Keanekaragaman Hayati Laut. Aset Pembangunan Berkelanjutan Indonesia”. Gramedia Pustaka Utama. Jakarta. Hal 38-52, 2003.

[2] P. A. L. Erftemeijer, "Factors limiting growth and production of tropical seagrass: Nutrients dynamics in Indonesia seagrass bed". Thesis Nijmegen Catholic University, Nijmegen the Netherland, 1993.

[3] S. F. Tuhumury, "Status Komunitas Lamun di Perairan Pantai Teluk Ambon 
Dalam. Ichthyos. Jurnal Penelitian Ilmu-Ilmu Perikanan dan Kelautan, vol 7. No. 2, pp.85-88, 2008.

[4] A. Irawan, R. Noorsalam dan Nganro, "Sebaran Lamun di Teluk Ambon Dalam" Jurnal Ilmu dan Teknologi Kelautan Tropis, vol. 8, No. 1, pp. 99114, 2016.

[5] T. Tomascik, A.J. Mah, A. Nontji, dan M. K. Moosa, "The Ecology of the Indonesian Seas Part Two," Periplus Edition, Singapore, 1997.

[6] M. H. Azkab, "Ada Apa dengan Lamun," Oseana vol. 31, No. 3, pp. 4555, 2006.

[7] C. M. Duarte, M. Merino, N. S. R. Agawin, J. Uri, M. D. Fortes, M. E. Gallegos, N. Marba, and M. A. Hemminga, "Root production and belowground seagrass biomass". Marine Ecology Progress Series, vol. 171, pp. 97-108, 1998.

[8] C. M. Duarte, N. Marbã, J. Cébrian, S. Enriquez, M.D. Fortes, M.E. Gallegos, M. Merino, B. Olesen, K. San-Jensen, J. Uri, and J. Vermaat. "Reconstruction of seagrass dynamics: age determination and associated tools for the seagrass ecologist". Mar. Ecol. Prog. Ser, vol. 107, pp. 195 - 209, 1994.

[9] A. H. Cunha and C. M. Duarte, “ Population age structure and rhizome growth of Cymodocea nodosa in the Ria Formosa (southern Portugal)," Mar. Biol, vol. 146, pp. 841 - 847, 2005.

[10] J. M. Brouns, "The plastochrone interval method for study of the productivity of seagrass: possibilities and limitation". Aquat. Bot vol.21, pp. $71-88,1985$.

[11] S. Cabaco, O. Ferrira and Rui Santos, "Population dinamics of the seagrass Cymodocea nodosa in Ria Formosa lagoon following inlet artificial relocation". Estuarine, Coastal and Shelf Science 87, pp. 510 - 516, 2010.

[12] M. A. Hemminga and C. M. Duarte, "Seagrass Ecology". Cambridge University Press. Cambridge, 2000.

[13] J. E. Vermaat, N. S. R. Agawin, C. M. Duarte, M. D. Fortes, N. Marba, and J. S. Uri, "Meadow Maintenance, Growth and Productivity of A Mixed Philippine Seagrass Bed". Marine Ecology Progress Series, vol.124, pp.215-225, 1995.

[14] N. Marba, M. E. Gallegos, M. Merino, and C.M. Duarte, "Vertical growth of Thalassia testudinum: seasonal and interannual variability". Aquatic Botany, vol 41, pp.1-11, 1994b.

[15] C. M. Duarte, J. Uri, N.S.R. Agawin, M. D. Fortes, J. E. Vermaat, and N. Marba, "Flowering frequency of Philippine seagrasses" Botanica Marina, vol.40, pp.497-500, 1997.

[16] C. I. Tupan, R. Pentury and Pr. A. Uneputty, "Population dynamics of seagrass Thalassia hemprichii in Tanjung Tiram Waters, Poka, Ambon Island, Indonesia" AACL Bio vol. 9, No. 6, pp. 1286 - 93, 2016.

[17] C. I. Tupan and Pr. A. Uneputty, "The growth and population dynamics of seagrass Thalassia hemprichii in Suli Waters, Ambon Island" IOP Conf. Series: Earth and Environmental Science, vol. 89, pp 1-8, 2017.

[18] C. M. Duarte, K. San-Jensen, "Seagrass colonization: biomass development and shoot demography in Cymodocea nodosa patches" Mar Ecol Prog Ser, vol.67, pp.297-305, 1990.

[19] Supriadi, D. Soedharma, dan R. F. Kaswadji, "Beberapa aspek pertumbuhan lamun Enhalus acoroides 
(Linn.F) Royle di Pulau Barrang lompo Makassar". Biosfera vol.23, No 1, pp. 1-8, 2006.

[20] C. I. Tupan, "Profil Kandungan Logam Berat Timbal $(\mathrm{Pb})$ di Prairan Pulau Ambon dan Respons Struktur Anatomi dan Fisiologi Lamun Thalassia hemprichii terhadap Logam Berat Timbal $(\mathrm{Pb})$ ". Disertasi. Pascasarjana. Fakultas Perikanan dan Ilmu Kelautan. UB, pp. $56-65,2014$.

[21] R. Ambo Rappe, D. L. Lajus and M. J. Schreider, "Heavy metal impact on growth and leaf asymmetry of seagrass, Halophila ovalis". Journal of Environmental Chemistry and Ecotoxicology, vol. 3, No.6, pp.149159, 2011.

[22] P. R. Purnama, T. Soedarti and H. Pumobasuki, "The effects of lead $\left[\mathrm{Pb}\left(\mathrm{NO}_{3}\right)_{2}\right]$ on the growth and chlorophyll content of seagrass [Thalassia hemprichii (ehrenb.) Ascherson] ex situ," Vegetos, vol. 28, No.1, pp. 9-15, 2015. 